\title{
The Fossilized Pronunciation of the /a/ Sound in the Speech of Advanced U.P.KAN English Students
}

\author{
Guillaume Marie Kanyandu Betu \\ Chef de Travaux \\ Université Pédagogique de Kananga
}

\begin{abstract}
Fossilization is a widespread phenomenon in second language learning and is commonly acknowledged in the field of Second Language Acquisition. This study aims to investigate a hypothetically fossilized feature in U.P.KAN (Université Pédagogique de Kananga) English learners' speech, specifically the pronunciation of the lae/ sound among U.P.KAN English Students. It attempts to display whether these students pronounce it properly or whether it is rather frequently substituted by alternative phoneme. The paper also has a stab at showing the circumstances behind fossilization. It is assumed that phonological fossilized errors made by our subjects result mainly from the language transfer. Pedagogical factors also contribute to the making of pronunciation errors and to their being fossilized. Furthermore, some pronunciation errors are inherited from teachers. Finally, to reduce fossilization of the sound [a], the study suggests applying 'choral and individual pronunciation', describing how the sound is made with the speech organs and, using the phonetic symbol to indicate the sound. The slight distortion of the [ce] towards central [E] will be imitated as an almost correct [ce] sound as well.
\end{abstract}

Key words: interlanguage, backsliding, stabilization, fossilization.

\section{Introduction}

Fossilization is a prevailing fact in second language learning that is, the phenomenon of fossilization in interlanguage, as proposed by Selinker in 1972 (Yang Yang, 2012), has drawn much attention and is commonly acknowledged in the field of Second Language Acquisition. Truthfully, as asserted by Qin Yang and Tujie Xu (2019), the interlanguage fossilization is a distinguishing characteristic of second language acquisition and plays an important role in promoting the foreign language teaching.

In fact, although it has been shown that there exists the ability to attain native like proficiency in morphology and syntax, the inability of many adult second language learners to achieve such proficiency in pronunciation has often intrigued linguists (Ellis, 1986; Long 1990). Therefore, it is of great significance for teachers and students to get a better understanding of fossilization and to overcome fossilization in English language learning. This paper aims to investigate phonological fossilization among English learners at U.P.KAN, a pedagogic university in the centre of the Democratic Republic of Congo.

In the field of linguistics and second language acquisition, there is the point of view already been supported by the proponents of the critical period hypothesis for second language learning which is based on the assumption that language learners before puberty are more likely than adults to speak a second or foreign language without a foreign accent.

In fact, since the subjects dealt with in this work are teenagers and adults, they are more likely to speak English with a foreign accent. On the other hand, Krashen (1973) quoted by Katsuva (1987:184) and other researchers believe that there is "a critical period phonetic learning" occurring long before puberty". This critical period explains the superiority of children over adults in second or foreign language pronunciation.

Considering the two hypotheses, age is undoubtedly the important factor which explains the discrepancy in phonological development between the young and the adult. However, mention should be made that age is not the sole factor explaining this difference. Flege (1981) quoted by Katsuva (1987:185) speaks of the simultaneity of learning. He believes that a young child who simultaneously learns two languages is likely to perform better in pronunciation than an adult who begins a second language after the establishment of the first language. This is explainable in the sense that the adult is bound to interpret sounds in the second or foreign language in terms of sounds occurring in his first language. That interpretation of foreign sounds by reference to one's first language sounds is what Flege has termed "phonological translation hypothesis' (Katsuva, 1987:185). 
As can be seen, from the above views on foreign accent in second or foreign language, pronunciation cannot be free from foreign accent. This is mainly caused by interference from the first language. It should be noted that our subjects' interlanguage is not made of two languages (first and target languages) but of more languages for they are placed in a multilingual setting; their English should be viewed as the output of all the languages already known before learning English. They are mainly Ciluba, French, Lingala and other tribal or ethnic languages.

\section{Literature Review}

\subsection{The concept 'Interlanguage'}

In fact, in the course of second language learning, the learner internalizes a complex set of rules, that is, a scheme or a system of rules. This system of rules may be different from both the target language and the source language. Hence, the learner's knowledge of the target language should be accounted for as a whole, it is in between first language and target language but reflects more the target language. The learner has then formed or constructed his own idiosyncratic dialect of which he is the only native speaker. This idiosyncratic dialect is regular, systematic and meaningful, that is to say, it has a grammar of which the set of rules shares the characteristics of two social dialects of language, whether these languages share rules or not as stated by Corder (1986:17). Selinker, cited by Corder (1986:66), gives to the learner's version of the target language the name of "interlanguage". James coined the term "interlingua", Nemser offered "approximate system", Corder refers to learners' "transitional competence" (Corder, 1986:66) and Krashen calls it "interlanguage talk". In fact, as explained by Corder (1986) interlingua and approximate system try to explain that the language produced by the acquirer will show systematic characteristics both the L2 and of other languages that he or she may be familiar with most obviously of the native tongue and interlanguage talk emphasizes that the learner possesses a certain body of knowledge which is constantly developing and underlies the utterances he makes.

According to Dulay, Burt, and Krashen (1982: 278), interlanguage is "a term used to refer to the speech or writing of second language learners in the second language". In this course of action, the learner makes use of the target language by way of the structures already established in his brain.

In addition, since SLA work done in the 1960's and 1970's (Ellis, 1986), interlanguage has been defined as a series of grammars developed by the language learner at different stages of the second language learning process. They go on stating that IL grammar can be systematic, permeable, transitional and discrete.

Interlanguage grammars are systematic in that they exhibit internal consistency. The interlanguage is a system to its own right with forms that neither belong to the first language nor the second language.

Though interlanguage is systematic, it also shows some degree of permeability which allows either for the transfer of rules, or forms from the native language to the interlanguage, as well as overgeneralizations of an improper IL rule in SL contexts (Ellis, 1986: 50). Interlanguages are transitional because they can change over time. The fact that interlanguage is progressive and dynamic implies that learners will keep on learning more, therefore over time their competence will change. However, Ellis (1986: 48) states that "just because systems are dynamic, this does not mean that there is no stability, or that everything is always in flux". Finally, Interlanguages are discrete in the sense that there are differences between an interlanguage grammar and subsequent Interlanguages, which can be developmental stages.

Of course, although it has been shown that there exists the ability to attain native like proficiency in morphology and syntax, the inability of many adult second language learners to achieve such proficiency in pronunciation has often intrigued linguists (Ellis, 1986; Long, 1990). Indeed, it is impossible for students to learn another language without establishing similarities between his or her L1 and the L2, and during the interlanguage stage learners make mistakes and errors. If not, they do not have the possibility to test out their progress in learning. In other words, taking into account the fact that the learner is meant to be learning the rules of the target language, then he will produce, as a matter of course, utterances which are ill-formed. These ill-formed utterances or errors are "regarded as useful evidence of how the learner is setting about the task of learning" (Corder, 1986:66). Indeed, errors are bound to happen and are actually a necessary part of the learning process. While conceiving interlanguage as being a continuum, Selinker also explicitly recognizes the process of regression, which he calls "backsliding". He speaks of the "regular reappearance of linguistic structures which were thought to be eradicated" (Corder, 1986:74). He goes on stating that at a certain stage, the learner interlanguage ceases to develop however long he remains exposed to authentic data in the target language and his errors become permanent or stable" (Corder, 1986:74). It is this state of affairs that Selinker calls "fossilization". Fidler (2006:398) states that "most adult second language learners never reach native-like proficiency in their target language". In their turn, Tollefson and Firn (1983), cited by Ghasemi (2003) hold the view that almost all adults second language learners fail to achieve native like competence and will fossilize somewhere along the interlanguage continuum. 
As can be noted, in second or foreign language learning research, fossilization is a concept that is fundamental to interlanguage and it is of such a great significance that Selinker (1972) believes it is a fundamental phenomenon of SLA. It therefore plays an important role in terms of errors in second or foreign language learning. In fact, fossilized errors are not easily eradicated and are the most important source of information about the learner's linguistic development and indispensable devices he uses to test hypotheses about the language he is learning. Indeed, both interlanguage and fossilization are coined by Selinker. The former is used to refer to the transitional or interim grammar that second or foreign language learners try to reconstruct in their way to the target language. It is as Stern (1983:355) argues, "a system created by the learner himself". It is in other words, the learner's structured system at a single point in time that is characterized by the development of learners in time, that is, either synchronic or diachronic. Corder (1986) argues that, in the interlanguage period, the phonetic and phonological systems of the language of the learner undergo several changes. The latter refers to a stagnant situation rather than developmental, not dynamic.

\subsection{Fossilization}

In fact, Corder (1986) asserts that the construct of fossilization dates back to scholars such as Weirnreich (1953) and Nemser (1971). The former talked about 'permanent grammatical influence' (Selinker, 1972:41) and the latter about 'permanent intermediate systems and subsystems' (Selinker, 1972: 174). The term 'fossilization' was brought into use in the realm of SLA knowledge by Selinker in 1972 on the basis of his observation that the vast majority of second language learners fail to achieve native-like competence.

From this conception of fossilization, it is worth mentioning that fossilizable structures are persistent, resistant to external influence and that they affect both child and adults L2 learners alike.

In 1978, Selinker and Lamendella (1978:187) redefined the notion of fossilization as: "... a permanent cessation of IL learning before the learner has attained TL norms at all levels of linguistic structure and in all discourse domains in spite of the learner's positive ability, opportunity, and motivation to learn and acculturate into target society".

From the stand point expressed above, fossilization is seen as permanent cessation of learning, going beyond the 'backsliding' of linguistics structures that were thought to be routed out.

Han (2004:15) adds that "the scope of 'fossilizable structures' was also extended from 'linguistic items, rules and subsystems' to 'all levels of linguistic structure and in all discourse domains'. The role by the 'learner's positive ability, opportunity, and motivation' was minimized, thereby suggesting the inevitability of fossilization and thus its innateness".

Selinker (1996) asserted that fossilization in the sense of a general cessation of learning would culminate in ultimate fossilized competence:

Fossilization is a process whereby the learner creates a cessation of interlanguage learning, thus stopping the interlanguage from developing, it is hypothesized, in a permanent way ... The argument is that no adult can hope to ever speak a second language in such a way that $\mathrm{s} / \mathrm{he}$ is indistinguishable from native speakers of that language.

In 1992, Selinker and Lakshmanan defined fossilization structurally in terms of persistent non-target structures, hence including long-term persistence as a defining characteristic of empirical discovering of fossilization (Han, 2004:15).

Considering the above standpoint, fossilization is inevitable; it is bound to happen and then cannot be avoided or evaded, thus, the ultimate attainment of adult L2 acquisition is a fossilized interlanguage; and hence no adult L2 learner would ever be able to pass for native in all contexts (Han, 2004:15).

In fact, apart from Selinker's definitions, some others have been proposed by many researchers since the notion of fossilization has been differently interpreted and thus a good variety of conceptions of fossilization has been brought into existence. Herein, we are going to give some of them which can be representative of the general views.

To begin with, Corder (1986:87) characterized fossilization as "a mechanism whereby speakers of a particular native language will keep certain linguistic items, rules, subsystems in their interlanguage, no matter what amount of instruction they receive in the target language".

Nemser (1971), cited by Corder (1986:88) has stated that "stable varieties of an approximate system are found when the learner has reached a plateau in his learning". It is this stabilization that Selinker names 'fossilization'.

In his turn Mc Laughlin (1987:61) defines fossilization as "the state of affairs that exists when the learner ceases to elaborate the interlanguage in some respects, no matter how long there is exposure, new data or new reaching". 
To sum up, as can be seen, the term 'fossilization' has been interpreted differently by different scholars and thus lacks a unified definition. As far as this study is concerned, one goes along with Han (2004:232) who sustains that throughout all the above mentioned definitions, two components should be focused, that is, (a) the tendency towards cessation of learning, (b) despite continuous exposure to input, adequate motivation and readiness to learn and sufficient opportunity for practice.

Or else fossilization (1) involves premature cessation of development in defiance of optimal learning conditions, and (2) fossilizable structures are persistent over time, against any environmental influences, including consistent natural exposure to the target language and pedagogic interventions. It is then in the light of these elements that this research will be conducted.

As for phonological fossilization, which is the concern of this paper, Wei (2008: 127) stated that "phonological fossilization refers to the repetition of phonological errors which result from the incorrect acquisition of pronunciation by L2, usually affected by L1." These phonological errors once made over and over again and in the long run, hang about stable in the erroneous manner; then phonological fossilization occurs.

\section{Research Design}

\subsection{Participants}

The participants of the study were 14 students from the Department of English at the Faculty of Arts \& Human Sciences of U.P.KAN in the Democratic Republic of Congo. These advanced learners of English were enrolled in the fifth year of English at the time of the experiment. Their ages vary between 21 and 28. They were eleven males and three females. The phonetics component at this department is dealt with in the first, second, and the third years. Students go through some aspects pertaining to place and manner of articulation, strong and weak forms, as well as some aspects of intonation and suprasegmental features in general. The experiment in the present study has two phases in it: time one and time two. The researchers recorded data on time one and then on time two. We asked the students to pronounce some words containing the sound /æ/. After one six months' period, the subjects were asked to pronounce the same words. The main goal was to see whether they pronounce the sound /æ / correctly or they rather replace it with other sounds.

\subsection{Procedure and Instrumentation}

To conduct this research, which is particularly based on the production of the /æ/ sound, the data which could provide us with some insights into the phonological system of our subjects were needed. Hence, the data consisted of recording some sample of speech obtained from sitting for pronunciation tests of which reading aloud list words and sentences. The words prepared in the word list were mostly common words in order to make the subjects feel more relaxed. Those words and sentences were designed to diagnose pronunciation difficulties of the subjects. Based on subjects' source languages (Ciluba and French), their pronunciation errors were diagnosed into the following categories: the absence of the English sound /æ/ in the source languages and the influence of the latter over the English language.

Before the recording process, the subjects were asked to familiarize themselves with the words and sentences through reading them once. The recording was conducted individually in a quiet room and took approximately five minutes for each subject. Each subject was required to read at a normal speed. Under the guidance of phonemic transcription in Cambridge English Pronouncing Dictionary, the recording was replayed many times and the pronunciation errors were noted. The pronunciation tests were administered during the class assignments time.

\section{Methodology}

In general, researchers have looked to persistence and resistance as key displays of fossilization. Some have sought stabilized deviant interlanguage of the advanced learners in the belief that what remained should be the most persistent and were therefore the most likely candidates for fossilization.

Indeed, empirical studies so far have adopted one, or a combination of more than one approach. As far as we are concerned, we have used the following methodological approaches in order to conduct our investigation: typical-error, advanced-learner and corrective-feedback.

\subsubsection{Typical Error Approach}

Kellerman (1989), quoted by Han (2004: 90), states that errors that typify a whole community of L2 learners with the same L1 background are the strongest candidates to fossilization. 
As argued by Han (2004), in typical-error approach, errors that are persistent in the interlanguage of learners with a homogeneous L1 background, usually across different proficiency levels, are studied. In other words, errors characteristic of learners having the same L1 background are acknowledged and analyzed to stain instances of fossilization".

As for our case, subjects have the same L1 background, that is, they have Ciluba and French as source languages and typical pronunciation errors were indicators of phonological fossilized errors in their interlanguage.

\subsubsection{Advanced-Learner Approach}

As can be noted from the headline, the advanced-learner approach brings into play advanced learners as the main source of information. In the same line of thoughts, Han '2004: 92) says that "the advanced-learner approach, as the name suggests, studies very advanced learners, usually, the so-called near-native speakers". Some researchers such as Hyltenstam (1988) turned to advanced learners or near-native speakers for evidence of fossilization. Their motivation was that whatever remained in the interlanguage of this group had been subject to long-term stabilization.

The research we have conducted has used, as informants, students who are in the fifth year of English, that is, their last of year of learning English and thus may be considered advanced-learners of which pronunciation errors found out in their interlanguage are the best index of phonological fossilization.

\subsubsection{Corrective-feedback Approach}

Researchers among whom Thep-Ackrappong (1990) used corrective feedback as a diagnostic of fossilization. Of course, L2 learners' reaction to corrective-feedback has also been employed as a means of determining whether the learner's erroneous usage of a particular linguistic form has fossilized or it is merely a temporary cessation of learning.

Apart from sporadic corrective feedback during different English courses, among which conversation, our subjects have systematic corrective feedback all through the three courses of Phonetics and Phonology extending from the first to the third year of English learning. Thus errors which seemed to have been immune to this pedagogical intervention, that is, corrective feedback, were bound to fossilization.

All things considered, this study is based on the conjugation of four approaches to the study of fossilization, namely typical-errors analysis, corrective-feedback, longitudinal approach and advanced-learner approach. As stated by Han (2004), "errors that are typical of a whole population with homogeneous L1 background are possible candidates for fossilization". As for corrective feedback, it is assumed that errors which are resistant to the pedagogic intervention should be the linguistic focal point for investigating fossilization. Furthermore, this study has adopted a longitudinal method of data collection in that learners at different proficiency levels are used as informants to provide a diachronic view of the interlanguage elements under search. At last, the advanced-learner approach has been used in so far as whatever remained in the interlanguage of L2/FL students had been subject to long-term stabilization.

\section{Results and Discussion}

The results of the study show that 5 students pronounced the /æ/ sound correctly. However, 9 students mispronounced the /æ/ sound and they replaced it with the /e / or /a / sounds as shown in the following figure:

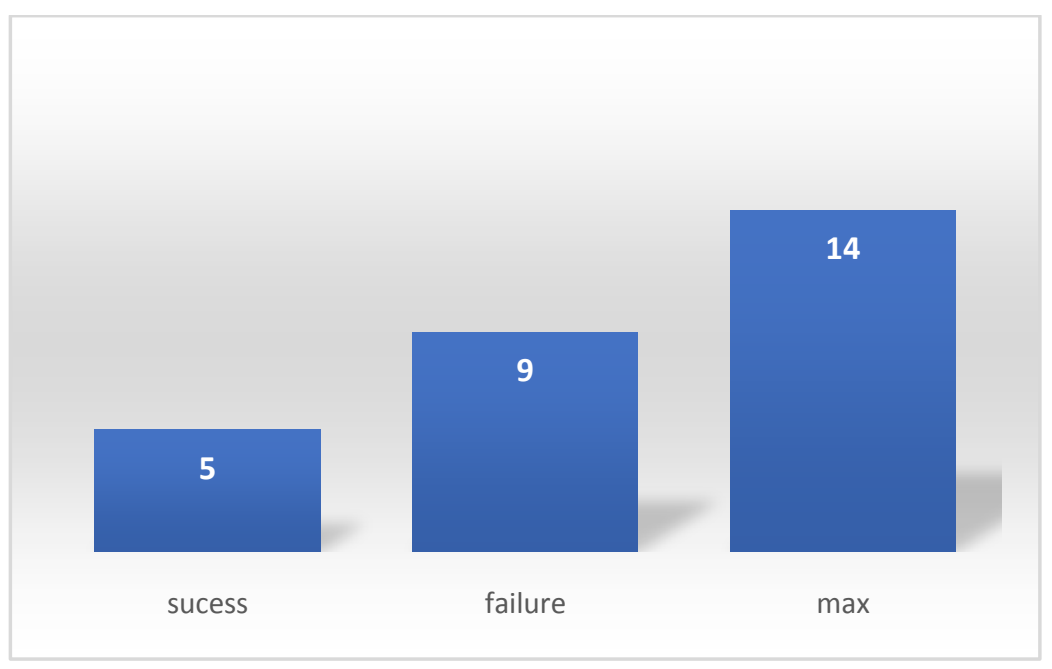




\subsection{The Source of Fossilized Pronunciation of the /a/ sound}

In fact, since the subjects dealt with in this work are teenagers and adults, they are more likely to speak English with a foreign accent. This point of view has already been supported by the proponents of the critical period hypothesis for second language learning which is based on the assumption that language learners before puberty are more likely than adults to speak a second or foreign language without a foreign accent.

Considering the two hypotheses, age is undoubtedly the important factor which explains the discrepancy in phonological development between the young and the adult. However, mention should be made that age is not the sole factor explaining this difference. Flege (1981) quoted by Katsuva (1987:185) speaks of the simultaneity of learning. He believes that a young child who simultaneously learns two languages is likely to perform better in pronunciation than an adult who begins a second language after the establishment of the first language. This is explainable in the sense that the adult is bound to interpret sounds in the second or foreign language in terms of sounds occurring in his first language. That interpretation of foreign sounds by reference to one's first language sounds is what Flege has termed "phonological translation hypothesis' (Katsuva, 1987:185).

As can be seen, from the above views on foreign accent in second or foreign language, pronunciation cannot be free from foreign accent. This is mainly caused by interference from the first language. It should be noted that our subjects' interlanguage is not made of two languages (first and target languages) but of more languages for they are placed in a multilingual setting; their English should be viewed as the output of all the languages already known before learning English. They are mainly Ciluba, French, Lingala and other tribal or ethnic languages.

This section examines to what extent first language transfer has made our subjects' English pronunciation fossilized and to which extent other factors be they linguistic, pedagogic or psychological have played the same role.

\subsubsection{Linguistic Factors}

Considering the linguistic factors which contribute to the interference in the acquisition of the English language phonological system by U.P.KAN learners of English, mention should be made of interlingual interference and intralingual interference. The former is caused by the linguistic background of the learner, that is, French and Ciluba, over the English language and the latter is caused by the structure of the English language itself.

\subsubsection{Interlingual Interference}

As to errors caused by interlingual interference, that is, errors resulting from the translation of English phonological system into source languages, mention should be made of the substitution of the English vowel / æ/ by the vowel segments[e] or [a] of the subjects' already known languages: $/ \mathfrak{x} / \rightarrow[\mathrm{e}]$ or $[\mathrm{a}]$

The similarity in spelling is another negative influence of the French language over English pronunciation. Therefore, most English words whose spelling is similar to the French one are probably to be pronounced with a French like accent. Such is the case of the word 'inhabitant' [In'hæbitənt] where the sound /æ/is pronounced as /a/ because of the similarity in spelling of the word 'inhabitant' with the French word 'inhabité' [inabite].

\subsubsection{Intralingual Interference}

As to errors caused by intralingual interference, that is, errors having their source in the target language itself, mention should be made of the inconsistency between the pronunciation and the spelling of English. In fact, there is no correspondence between the phonetic symbol and the spelling one. Such is the case of / æ / in 'back' and'cat'.

\subsubsection{Pedagogic Factors}

In fact, in the town of Kananga, which is the setting of our subjects, English is learned and/or taught in an artificial environment, that is, the classroom. No opportunity is then offered to our subjects to practise language outside the classroom. This artificiality of the classroom teaching somehow contributes to the failure in English pronunciation, e.g., learners do not have the authentic exposure in their learning of English. Teachers' incompetence and the lack of didactic materials such as audio-visual aids (cassette records, CDs, radio, TV or video) and even more the most basic English book in pronunciation contribute to the phonological fossilization process in our subjects' learning of English as well. Furthermore, because of the artificial environment English teachers have been trained in; some pronunciation errors in the learners' English are directly inherited from the teacher himself especially if he is not qualified.

\subsubsection{Psychological Factors}


As far as the psychological factors are concerned, the lack of didactic materials may cut off the learner's interest in improving English pronunciation and therefore his level of aspiration is either decreased or lost. He consequently cannot master English pronunciation without errors since he is not motivated in his learning.

Another psychological factor, previously discussed is age. As already said, since our subjects are teenagers and adults, they are more likely to speak English with a foreign accent. As can be seen, the belief is based on the critical period hypothesis on the one hand and on the critical period for phonetic learning on the other hand.

\subsection{Suggested Remedies}

As Selinker (1972) points out, the most important fact concerning L2 phonology is the phenomenon of fossilization. According to Scovel (1969), adult language learners maintain a typical accent which is indicative of their first language (L1). He has named this the 'Joseph Conrad Phenomenon' after the prominent British author who achieved native-like fluency in English syntax (his L2) but retained a Polish accent (his L1). $\quad$ As can be noticed, considering the interlanguage theory, fossilized errors are part of the learner's interlanguage. They are known as being permanent or stable and therefore not easily to be eradicated. Nevertheless, given the fact that "remedial teaching becomes necessary when we detect a mismatch between the knowledge, skill or ability of someone and the demands that are made on him by the situation he finds himself" (Corder, 1986:45), an attempt to correct fossilized errors should be encouraged.

Of course, the English RP vowel / æ / is pronounced with the mouth slightly more open than for / e /; the front of the tongue is raised just below the half-open position; the lips are neutrally open. The quality is nearer to central $[\mathcal{E}]$ than to central [ə]. Hence, there is a danger of confusing RP /æ/ either with [a:] if length quality is overestimated, or with [e] if that length is underestimated.

As for the subjects, this sound is realized as $[\varepsilon]$ by most of them. Thus, words such as black, back, cat are respectively pronounced [blEk, bEk, kEt]. The sound [E] can be described as front, similar to Luba / $\mathcal{E}$ / as in 'kele' / $\mathrm{kElE} /$ ' $\mathrm{knife}$ or French / $\mathcal{E} /$ in 'sèche' [sEJ] 'dry'. It is produced with the front of the tongue raised to a height a bit lower than of English / e /.

As to the environment in which the substitution of [E] for the English /æ /occurs, mention should be made that this substitution is systematic in both monosyllabic and polysyllabic words. It should be noted, however, as the data show, that some of the subjects realize [æ] as [a] in English words whose spelling is similar to French. Such words as 'rat, match, garage, accident and camp are respectively pronounced [ rat, mat , garad3, aksidEnt, kamp].

As stated by Schollaert (1976:68), correction in this case will hardly succeed if only the environment is used because / $æ$ / is quite close to the learner's / $\mathcal{E}$ / and / a / phonemes, what they should be brought to is a correct perception. That is to say that a slight distortion of the [æ] towards central $[\mathcal{E}]$ will be imitated as an almost correct [æ] sound. (Schollaert, 1976:63). Discrimination drills should also be provided.

\begin{tabular}{|c|c|}
\hline $\operatorname{man}$ & men \\
\hline bad & bed \\
\hline bat & bet \\
\hline mass & mess \\
\hline had & head \\
\hline gas & guess \\
\hline pan & pen \\
\hline jam & gem \\
\hline band & bend \\
\hline
\end{tabular}

Do you know the men/man who did this?

There were several pens/pans in the cupboard.

They were waiting for us near the bend/band.

$\mathrm{He}$ sat/set to work

It's a famous band/bend.

John and George were both there but the latter/letter wasn't read.

Furthermore, the teacher should make use of choral pronunciation for it serves to bring the class together. The ideal solution is what Lewis and Hill (1985:67) call "choral and individual pronunciation" (c.i.p.). That is to say the class repeats in chorus the model pronunciation provided by the teacher and thereafter the teacher asks learners to reproduce it individually. 
On the other hand, Oliva (1969:100-109) supplements the repetition of the sound by additional techniques such as: describing how the sound is made with the speech organs; providing adequate practice in the formation of the sound and using the phonetic symbol to indicate the sound.

\section{Appendix:}

Corpus: 45 words

$\begin{array}{lllll}\text { Bad } & \text { man } & \text { bat } & \text { had } & \text { bag } \\ \text { Band } & \text { pan } & \text { hat } & \text { rat } & \text { cat } \\ \text { mass } & \text { cab } & \text { sad } & \text { mat } & \text { pad } \\ \text { pat } & \text { lack } & \text { natural } & \text { angelic } & \text { bad } \\ \text { mad } & \text { lap } & \text { dad } & \text { fat } & \text { gap } \\ \text { garage } & \text { back } & \text { sat } & \text { crack } & \text { accident } \\ \text { Clap bang } & \text { snap } & \text { tap } & \text { lid } \\ \text { Chance chap } & \text { mishap lad } & \text { angry } \\ \text { Slam lad } & \text { cabin } & \text { hack } & \text { wad }\end{array}$

\section{Conclusion}

Of course, the organization of sounds plays a greater role in communication than the sounds themselves. Thus pronunciation is important for oral communication and is also linked with other skills such as listening comprehension, grammar and reading. Consequently, pronunciation bears important information that can support these skills. Indeed, errors are bound to happen and are actually a necessary part of the learning process. It is thus crucial to find out the errors that learners make and study them since they are "regarded as useful evidence of how the learner is setting about the task of learning" (Corder, 1986:66). U.P.KAN students face the problem of Fossilization and the present study endeavored to tackle this problem. The results showed how the /æ/ sound is replaced by the /e / or /a / sounds and how the phenomenon becomes 'fossilization' in the speech of U.P.KAN students. After the investigation, the phonological fossilized errors made by our subjects result mainly from the language transfer. Pedagogical factors such as teachers' incompetence, lack of teaching aids..., in another way, also contribute to the making of pronunciation errors and to their being fossilized. Furthermore, some pronunciation errors are inherited from teachers. Other factors and processes not mentioned herein may also be at the basis of such fossilized errors. To handle this issue, a slight distortion of the $[æ]$ towards central $[\mathcal{E}]$ will be imitated as an almost correct $[æ]$ sound. (Schollaert, 1976:63). Discrimination drills should also be provided.

\section{References}

CORDER, S.P. (1986). Error Analysis and Interlanguage, Oxford, OUP. DULAY, H., BURT, M., KRASHEN, S. (1982). Language Two. New York: Oxford University Press.

ELLIS, R. (1986) Understanding Second Language Acquisition, Oxford: Oxford University Press.

FIDLER, A. (2006) "Reconceptualizing Fossilization in Second Language Acquisition: a review" in Second Language Research. Second Language Research 22,3 (2006); pp. 398-411 FLEGE, S. (1981) The Phonological Basis of Foreign Accent: A hypothesis. TESOL Quarterly, 15, 443-455.

GAHSEMI, Z. (2003). The Role of Attention and in Adult Second Language Learning: A Thesis Submitted in Partial Fulfillment of the Requirements for the Degree of Master of Arts. School of Linguistics and Applied Languages Studies. Carleton University.

Ottawa, Ontario HAN, Z. (2004). Fossilization: five central issues International Journal of Applied Linguistics Vol. 14 w No. 2: 212 - 242.

HAN, Z-H. (2004). Fossilization in Adult Second Language Acquisition. Clevedon, UK: Multilingual Matters.

HYLTENSTAM, K. (1988) Lexical Characteristics of Near-native Second Language Learners of Swedish. Journal of Multilingual and Multicultural Development 9: 67-84.

KATSUVA, N. (1987). An Analysis of Pronunciation Errors in the Acquisition of English by Nande Native Speakers. Unpublished PhD dissertation, Essex University.

KELLERMAN, E. (1989) The Imperfect Conditional: Fossilization, Cross Linguistic Influence and Natural Tendencies in a Foreign Language Setting. In K. Hyltenstam and L. Obler (eds.), Bilingualism across the life span. Cambridge University Press. 887-115.

LEWIS,M., \& Hill. 1985. Practical techniques for Language Teaching, London: Language Teaching Publication.

LONG, M. (1990). Maturational Constraints on Language Development. Studies in Second Language Acquisition 12:225-285. 
Mc LAUGHLIN, M.B. (1987) Theories of Second Language $\quad$ Learning, Arnold. $\quad$ OLIVA, P.F. (1969) The Teaching of Foreign Language, New Jersey: Practice Hall, Uno, Engle- Wood Cliffs.

SCHOLLAERT, E. (1976). "Phonetic Correction in Teaching English to Zaïrians." Lubumbashi, CELTA, Collection Travaux et Recherches.SCOVEL, T. (1969). Foreign accents, Language Acquisition, and cerebral dominance. Language Learning 19:245-254.

SCOVEL, T. (1969). Foreign accents, Language Acquisition, and cerebral dominance. Language Learning 19:245-254.

SELINKER, L. (1996). Fossilization: What We Think We Know. London: Longman Groups UK Limited.

SELINKER, L. (1972) Interlanguage. IRAL 10 (2), 209-31.

SELINKER, L. and LAMENDELLA, J.T. (1978). Two Perspectives on Fossilization in Interlanguage Learning. Interlanguage Studies Bulletin, 3(2), 143-191.

STERN, H.H. (1983). Fundamental Aspects of Language Teaching, Oxford: OUP.

THEP-ACHRAPONG, T. (1990)Fossilization: a case study of practical and theoretical parameters. Unpublished doctoral dissertation, Illinois state University.

WEI, X. (2008). "Implication of IL Fossilization in Second Language Acquisition" in English Language Teaching, Vol. 1, N $\mathrm{N}^{\circ} 1$ pp. $127-131$.

WEINREICH, U. (1953). Languages in Contact. Publication of the Linguistic Circle of New York, no. 1.

YANG YANG, E. (2012). Fossilization in Chinese Students' English Language Acquisition. Seminar Paper Presented at the Graduate Faculty. University of Wisconsin Platteville. Retrieved from http://digital.library.wisc.edu/1793/614437

YANG, Q. and XU, T. (2019). English Reform in Local Undergraduate College in Theory and Practice in Language Studies, vol. 9, NO 3. Retrieved from http.www.academypublication.com/ 